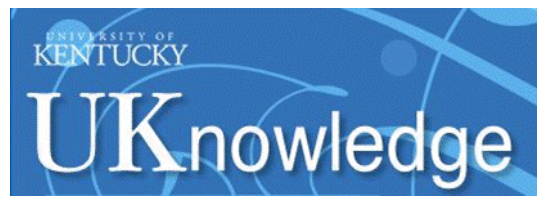

University of Kentucky

UKnowledge

Biosystems and Agricultural Engineering Faculty Publications

2016

\title{
As-Applied Estimation of Volumetric Flow Rate from a Single Sprayer Nozzle Series Using Water-Sensitive Spray Cards
}

\author{
Michael P. Sama \\ University of Kentucky, michael.sama@uky.edu \\ John T. Evans \\ University of Nebraska - Lincoln \\ Aaron P. Turner \\ University of Kentucky, aaron.turner@uky.edu \\ Surya Saket Dasika \\ University of Kentucky, surya.dasika@uky.edu
}

Follow this and additional works at: https://uknowledge.uky.edu/bae_facpub

Part of the Agriculture Commons, and the Bioresource and Agricultural Engineering Commons

Right click to open a feedback form in a new tab to let us know how this document benefits you.

\section{Repository Citation}

Sama, Michael P.; Evans, John T.; Turner, Aaron P.; and Dasika, Surya Saket, "As-Applied Estimation of Volumetric Flow Rate from a Single Sprayer Nozzle Series Using Water-Sensitive Spray Cards" (2016). Biosystems and Agricultural Engineering Faculty Publications. 139.

https://uknowledge.uky.edu/bae_facpub/139

This Article is brought to you for free and open access by the Biosystems and Agricultural Engineering at UKnowledge. It has been accepted for inclusion in Biosystems and Agricultural Engineering Faculty Publications by an authorized administrator of UKnowledge. For more information, please contact UKnowledge@lsv.uky.edu. 


\section{As-Applied Estimation of Volumetric Flow Rate from a Single Sprayer Nozzle Series Using Water-Sensitive Spray Cards}

\section{Digital Object Identifier (DOI)}

https://doi.org/10.13031/trans.59.11538

Notes/Citation Information

Published in Transactions of the ASABE, v. 59, issue 3, p. 861-869.

(C) 2016 American Society of Agricultural and Biological Engineers

The copyright holder has granted the permission for posting the article here. 


\title{
AS-APPLIED ESTIMATION OF VOLUMETRIC FLOW RATE FROM A SINGLE SPRAYER NOZZLE SERIES USING WATER-SENSITIVE SPRAY CARDS
}

\author{
M. P. Sama, J. T. Evans, A. P. Turner, S. S. Dasika
}

\begin{abstract}
The objective of this study was to test the feasibility of using coverage measurements from water-sensitive spray cards to estimate the volumetric flow rate at an individual sprayer nozzle. TeeJet VisiFlow Even Flat Spray Tips were selected due to their uniform distribution of coverage. Spray distribution for each nozzle was validated using a spray patternator table with $2.5 \mathrm{~cm}$ sampling widths. A rotary test fixture translated water-sensitive spray cards through the spray dispersion (water at ambient conditions) at a constant angular velocity and a radius of $1.2 \mathrm{~m}$. The test fixture measured volumetric flow and pressure at the nozzle and recorded data at a rate of $10 \mathrm{~Hz}$. A helical gear pump and a pistontype pressure regulating valve were used to provide constant pressure. The first experiment fixed the test fixture speed at $3.14 \mathrm{rad} \mathrm{s}^{-1}$ and used varying pressures from 70 to $552 \mathrm{kPa}$ (10 to $80 \mathrm{psi}$ ) in $70 \mathrm{kPa}$ (10 psi) increments. First-order and second-order regression models were developed for the nozzle series, and validation data were collected at intermediate pressures to test the ability of the model to predict volumetric flow rates. The second experiment fixed the system pressure at $310 \mathrm{kPa}(45 \mathrm{psi})$ and varied the speed of the test fixture at seven increments between 2.0 and $3.8 \mathrm{rad} \mathrm{s} \mathrm{s}^{-1}$. Spray cards were digitized using a scanner and processed for coverage using the MATLAB image processing toolbox. Results showed that the accuracy of the spray card method was within $1 \%$ full-scale of a commercial impeller flowmeter for a single series of nozzles moving at constant speed. Varying speed could be accounted for but required knowledge of the individual nozzle model. The method demonstrated in this study may be useful for field validation of variable-rate control systems on agricultural sprayers.
\end{abstract}

Keywords. Flow measurement, Precision agriculture, Spray card, Sprayers, Water-sensitive paper.

$\mathrm{T}$ The concept of using a target material for collecting and evaluating liquid spray for agricultural applications has been well documented. Turner and Huntington (1970) developed the process of incorporating a dye solution onto a paper that changed color from yellow to blue when exposed to water. Spray cards, or water-sensitive paper (WSP) as they are commonly referred to, have primarily been used for as-applied analysis of spray coverage, where the percentage of the spray card that is exposed by contact is the measured coverage. The spray card is typically scanned or digitized and analyzed using an image processing algorithm, which has replaced manually observing and estimating spray coverages. Research has shown that visual estimations of coverage densi-

Submitted for review in September 2015 as manuscript number MS 11538; approved for publication by the Machinery Community of ASABE in February 2016.

The authors are Michael P. Sama, ASABE Member, Assistant Professor, Department of Biosystems and Agricultural Engineering, University of Kentucky, Lexington, Kentucky; John T. Evans, ASABE Member, Graduate Research Assistant, Department of Biological Systems Engineering, University of Nebraska-Lincoln, Lincoln, Nebraska; Aaron P. Turner, ASABE Member, Engineer Associate, and S. Saket Dasika, ASABE Member, Undergraduate Research Assistant, Department of Biosystems and Agricultural Engineering, University of Kentucky, Lexington, Kentucky. Corresponding author: Michael P. Sama, 119 C.E. Barnhart Bldg., University of Kentucky, Lexington, KY 40546-0276; phone: 859-218-4325; e-mail: michael.sama@uky.edu. ty on a spray card had a tendency to exceed the coverage calculated using image processing methods (Fox et al., 2003), whereas image processing methods were shown to be accurate to within $3.5 \%$ of the actual coverage (Panneton, 2002). Tools have been developed for field analysis of water-sensitive spray cards to provide a rapid assessment of spray quality and coverage (Franz, 1993; Zhu et al., 2011). Further work compared multiple commercial imaging systems and found that results were consistent when relating droplet diameter to the diameter of the stain on a spray card (Hoffmann and Hewitt, 2005).

Automatic nozzle and section control is a common practice for mitigating overlaps between parallel passes and when entering and existing point rows. Individual nozzles or groups of nozzles are selectively controlled in real-time based on a prescription and as-applied maps. The process of turning nozzles on and off has been shown to have a significant effect on the volumetric flow rate of nearby nozzles, resulting in off-rate errors of up to $10 \%$ (Sharda et al., 2010) and decreasing uniformity (Sharda et al., 2011). Much of this error was determined to be due to response time in the sprayer rate controller as the system adjusted for step changes in the overall required flow rate.

Varying speed and turning maneuvers are another source of error between desired and actual application rates (Jeon et al., 2004; Luck et al., 2011; Speelman and Jansen, 1974). Modern systems are capable of controlling sprayer booms 
at the individual nozzle level. These variable-rate spraying systems modulate the application rate based on prescriptions and compensate for changes in speed-over-ground or due to turning movements. The large number of nozzles on a typical high-clearance self-propelled sprayer makes validating individual nozzle control of the entire system costprohibitive. It is common for only a subset of nozzles to be instrumented for pressure, which is used to estimate flow based on manufacturer or laboratory derived calibration curves (Sharda et al., 2010). The wide range of flow rates that can be achieved across a nozzle series at varying system pressures also presents a challenge for accurate flow measurement. Measuring flow rate at the nozzle provides input for sprayer control but is not suitable for assessing asapplied performance because it fails to account for external factors that contribute to spray drift, such as nozzle height and wind speed (Smith et al., 2000) or evaporation, which can vary due to the spray liquid properties and ambient conditions (Williamson and Threadgill, 1974). Alternative methods for measuring the as-applied performance of variable-rate sprayer systems are needed.

The overall objective of this study was to test the feasibility of using coverage measurements from spray cards to estimate the volumetric flow rate at an individual sprayer nozzle. Specific objectives were as follows:

1. Instrument an individual nozzle for pressure and flow measurement and control.

2. Build a test fixture for accurately controlling the speed of a spray card under a nozzle.

3. Determine the relationship between spray card coverage and flow rate for a single nozzle series ranging from fine to coarse droplet sizes at a single height.

4. Determine if travel speed can be compensated for when estimating flow rate from coverage.

\section{Materials And Methods}

\section{LIQUID FLOW COMPONENTS}

A series of stainless steel nozzle tips (TP800xEVS VisiFlo Even Flat Spray Tips, TeeJet, Springfield, Ill.) were selected due to their uniform coverage characteristics. Nozzle tips were mounted on a diaphragm check valve body (22251-311-750-NYB, TeeJet, Springfield, Ill.), which minimized drips when turning the system off. Flow was provided by a helical rotor pump (101B, Oberdorfer Pumps, Syracuse, N.Y.), and pressure was controlled using a piston-type regulating valve (23120, TeeJet, Springfield, Ill.). Flow and pressure were monitored with an impeller flowmeter (FPR301, Omega, Stamford, Conn.) and a pressure transducer (PX181-100G5V, Omega, Stamford, Conn.), respectively. Flow was selectively enabled using a proportional solenoid valve (EV260B10, Danfoss, Baltimore, Md.) controlled by a 4 to $20 \mathrm{~mA}$ signal. For this study, flow was either fully on (20 mA) or fully off (4 mA).

\section{ROTARY TEST FIXTURE}

Spray cards (52 mm $\times 76 \mathrm{~mm}$, Syngenta, Basel, Switzerland) were translated under a fixed nozzle location, approximately $76 \mathrm{~cm}$ below the nozzle and $5 \mathrm{~cm}$ off center along the direction of spray, using a rotary test fixture. This configuration resulted in a sampling width of approximately $6 \%$ of the total spray width on a distance basis, a figure that will increase on a volume basis, depending on the spray pattern, due to lower flow rates toward the ends of the spray band. The height was chosen to match the manufacturer-recommended operating height, and the horizontal offset was to prevent drips when the nozzle was turned off from accidentally exposing the spray card. The rotary test fixture was a modification of the system used by Sama and Stombaugh (2014) for dynamic GNSS testing, which allowed the operator to control the speed and direction of a rotating armature from a personal computer (PC) connected to an embedded controller (Sama et al., 2013). The embedded controller firmware was updated to add functionality for this experiment. Specifically, analog voltage (pressure) and digital frequency (flow rate) measurements were passed through the serial port, and a hardware PWM output was used in conjunction with a PWM-to-analog (mA) converter to control the position of the solenoid valve. The entire test setup including liquid flow components is shown in figure 1. An adjustable frame suspended the nozzle at the desired height above the rotary test fixture and provided mounting for the flowmeter, solenoid valve, and pressure sensor. The spray card was held in place using a springloaded clip with the same outside dimensions as the spray card to ensure consistent positioning.

A single test consisted of opening the solenoid valve, setting the system pressure, accelerating the spray card to the desired angular velocity in less than one rotation, passing underneath the spray nozzle, closing the solenoid valve, and decelerating until motion ceased. The rotary test fixture had a radius of $1.2 \mathrm{~m}$ to the center of the spray card. Figure 2 illustrates the aforementioned process of a single test with a $3.14 \mathrm{rad} \mathrm{s}^{-1}$ step input. The rotary test fixture accelerated to $3.14 \mathrm{rad} \mathrm{s}^{-1}$ in approximately $0.5 \mathrm{~s}(<1 \mathrm{rad})$, remained at that constant angular velocity for $1.6 \mathrm{~s}(5 \mathrm{rad})$, and then decelerated until rest. The spray nozzle was located at $4 \mathrm{rad}$ relative to the rotary test fixture starting angle. The angular position of the rotary test fixture reset to zero after reaching $2 \pi \mathrm{rad}$.

Testing under static nozzle conditions using a dynamic spray card was chosen to simplify the test fixture that provided movement between the nozzle and spray card. Reversing the system by translating a nozzle across a static spray card may produce different results, particularly if the velocity vector of the droplets with respect to the spray card changes.

\section{Nozzle SPRAY DistribUTION}

A spray card located at the recommended distance from a single nozzle only represented a small portion of the actual spray width. Therefore, the spray distribution of each nozzle used in this study was quantified to understand how spray card location underneath a nozzle may affect volumetric flow rate estimations. Nozzles were mounted $76 \mathrm{~cm}$ (30 in.) above a patternator table consisting of $2.54 \mathrm{~cm}$ (1 in.) flow channels (fig. 3). Specifications of the spray patternator table were similar to those used by Luck et al. (2016) using the manual measurement technique. A row of graduated cylinders was mounted on a rotating frame, 


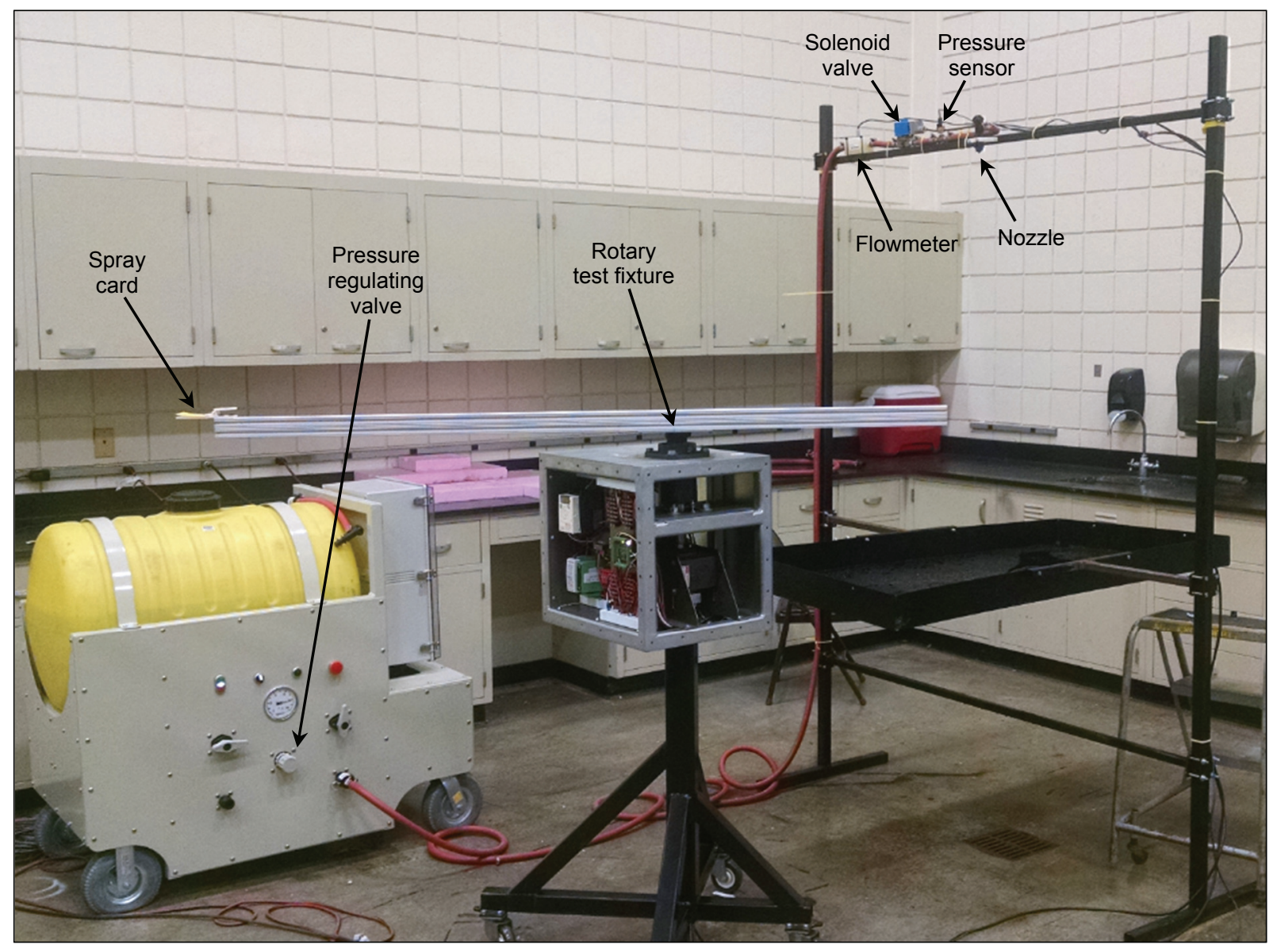

Figure 1. Test setup for controlling liquid pressure, liquid flow, and spray card speed under a spray nozzle.

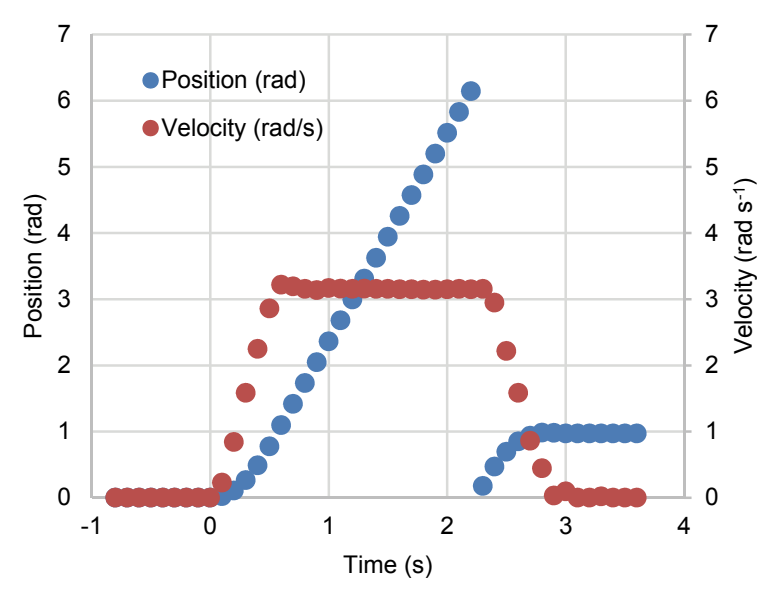

Figure 2. Rotary test fixture step response (input at $t=0 \mathrm{~s}$ ).

which allowed the cylinders to selectively collect spray effluent. Distribution data were collected at eight pressures ranging from 70 to $552 \mathrm{kPa}$ (10 to $80 \mathrm{psi}$ ) in $70 \mathrm{kPa}$ (10 psi) increments. Pressure was manually set during each test, and the system was allowed to stabilize for several minutes until the flow from each channel on the patternator table had reached steady-state. The graduated cylinders were moved into position to collect the spray effluent from the channels while a stopwatch was started simultaneously.
Once the graduated cylinder with the largest amount of liquid reached approximately $90 \%$ maximum level, the cylinders were removed and the elapsed time was recorded. The resulting liquid volumes were divided by the elapsed time to compute volumetric flow rates. Three replications for each pressure were averaged to reduce operator error associated with starting/stopping the stopwatch and reading the graduated cylinders.

\section{Spray Card Data Collection}

Three sets of data were randomly collected with three replications, one for developing a model to predict nozzle flow rate from coverage, one to validate the model, and one to test the influence of varying angular velocity. Calibration data were collected in $70 \mathrm{kPa}$ (10 psi) increments from 70 to $552 \mathrm{kPa}$ (10 to $80 \mathrm{psi})$ at an angular velocity of $3.14 \mathrm{rad}$ $\mathrm{s}^{-1}$. Validation data were collected in $70 \mathrm{kPa}(10 \mathrm{psi})$ increments from 103 to $517 \mathrm{kPa}$ (15 to $75 \mathrm{psi}$ ) at an angular velocity of $3.14 \mathrm{rad} \mathrm{s}^{-1}$. Data at seven angular velocities varying between 2.0 and $3.8 \mathrm{rad} \mathrm{s}^{-1}$ were collected at a constant system pressure of $310 \mathrm{kPa}$ (45 psi). A label was applied to each spray card immediate after each test that identified the nozzle, test parameters, and replication. All ana$\log$ and digital signals were measured by a digital signal processor (dsPIC18F4011, Microchip Technology, Inc., Chandler, Ariz.) and transmitted at a rate of $10 \mathrm{~Hz}$ via RS232 to a data collection PC. A Visual Basic program (Visu- 


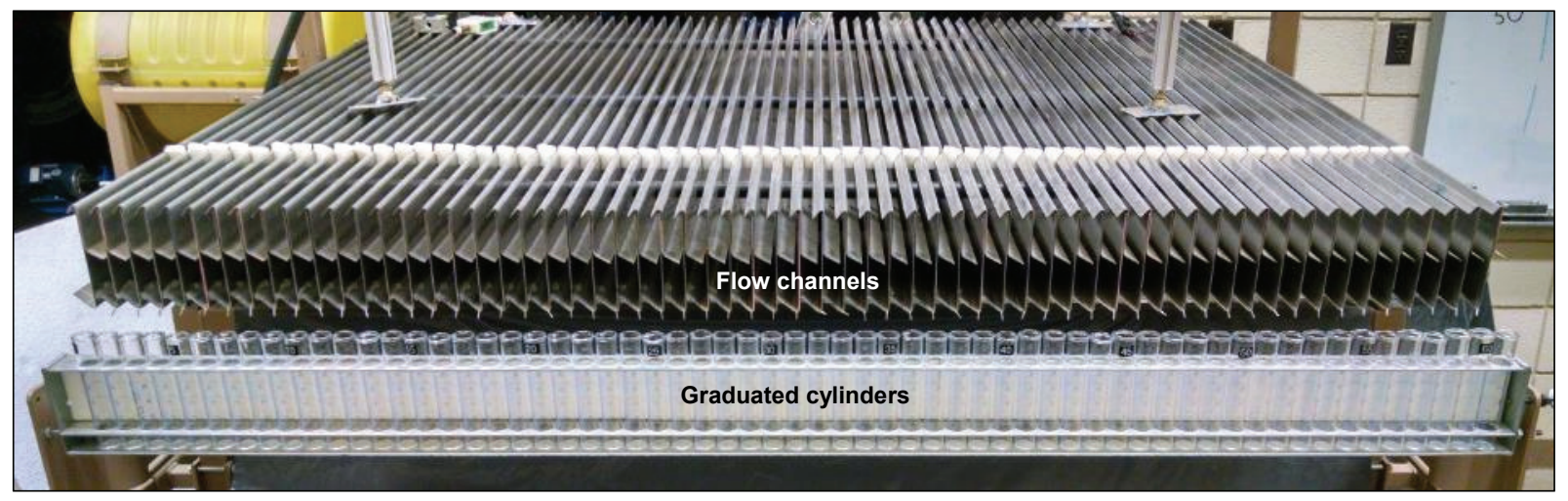

Figure 3. Spray patternator table with $2.54 \mathrm{~cm}(1 \mathrm{in}$.) spatial resolution.

al Studio 2010, Microsoft Corp., Redmond, Wash.) recorded the data stream in a comma separated value (CSV) file. System pressure and flow rate for each test were determined by computing the respective averages during the entire test. Angular velocity was computed as the average angular velocity once the rotary test fixture reached steadystate (within $2 \%$ of final value). The spray cards were digitized within $24 \mathrm{~h}$ of initial exposure on a flatbed scanner (V600, Epson America, Inc., Long Beach, Cal.) at $4800 \times$ 4800 dpi resolution (fig. 4).

\section{Data Processing ANd ANALYsis}

A spreadsheet containing the spray card file names, test fixture speed, system flow rate, and system pressure was read into MATLAB (R2014b, The MathWorks, Inc., Natick, Mass.). Spray card images were imported and cropped to remove the borders and label. Cropped images were binarized by converting the image to grayscale and then applying threshold to assign a value of 0 or 1 to pixels based on their intensity (fig. 5). A value of 0 corresponded to the unexposed background, and a value of 1 corresponded to the exposed droplet.

Coverage area was calculated as the ratio of the number of pixels exposed to water divided by the total number of pixels. The binary image was also fed into the Image Processing Toolbox regionprops function to calculate additional parameters, such as area and eccentricity for every droplet. First-order and second-order regression models were fit to the calibration data using least mean squares regression between the volumetric flow rate and spray card coverage. The models were then used to predict the flow rate based on spray card coverage of an independent valida-
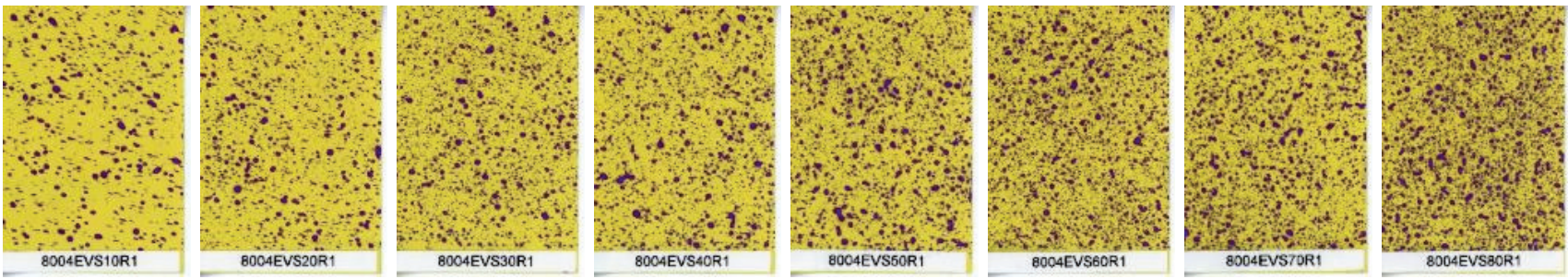

Figure 4. Exposed spray cards from a single nozzle at pressures from 70 to $552 \mathrm{kPa}$ (10 to $80 \mathrm{psi})$.

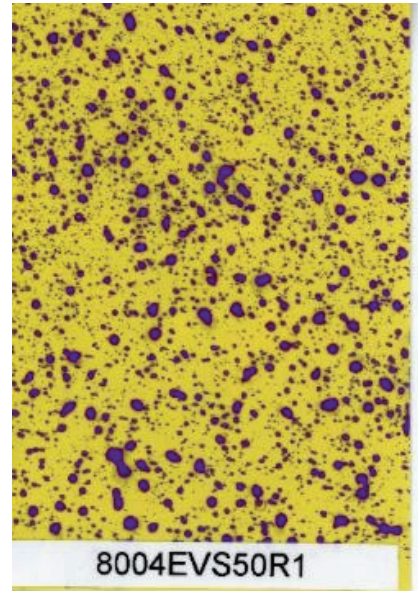

Original image

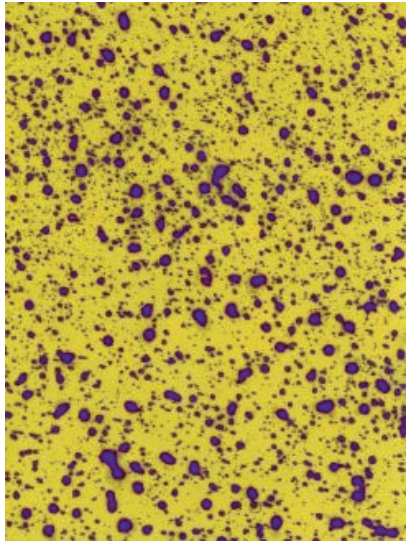

Cropped image

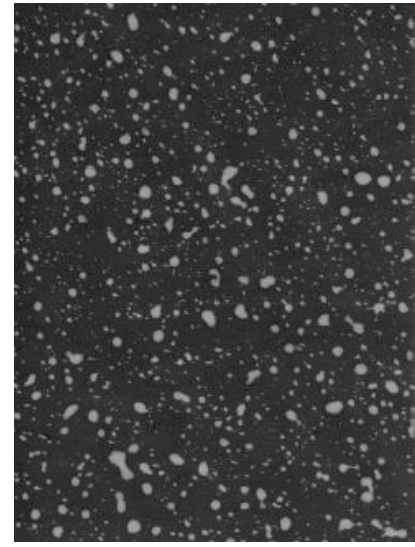

Grayscale image

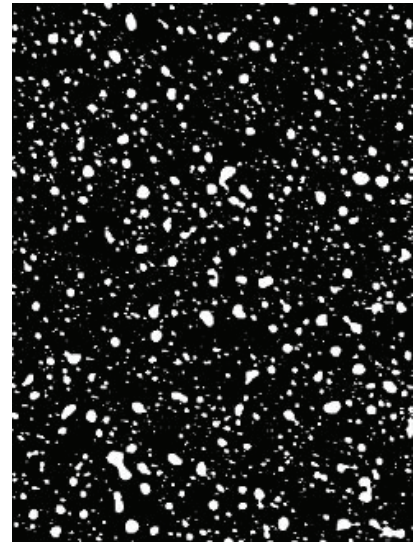

Binary image

Figure 5. Spray card image preparation steps. 
tion dataset and to test the variability in spray card coverage with respect to travel speed.

\section{RESULTS AND DISCUSSION \\ NOZZLE SPRAY DISTRIBUTION}

Results from the nozzle spray distribution tests verified the uniformity for most nozzles at varying pressures. The coarser nozzles produced the most uniform coverage across all pressures, and the lower flow rates resulted in the least uniform coverage across all nozzles. Figures 6 through 8 illustrate the distribution for three of the nozzles that produced fine, medium, and coarse droplet spectra. Each point represents an individual flow measurement integrated across discrete $2.54 \mathrm{~cm}$ widths.

While most distributions were uniform across the central portion ( $\pm 40 \mathrm{~cm}$ from the nozzle), the fine nozzle distribution was substantially different at low pressures. Under these conditions, the flow rate directly underneath the nozzle position was approximately twice as large as the flow rate $40 \mathrm{~cm}$ in either direction. A key assumption for this study was that the volumetric flow rate near the center of the nozzle, as estimated by coverage on a spray card, could be used to represent the volumetric flow rate of the entire nozzle due to the uniform distribution. The non-uniformity in the distribution for fine nozzles at low pressures will make estimating volumetric flow rate of the entire nozzle from a small portion of the distribution less accurate. Note that the nozzle manufacturer recommended a minimum operating pressure of $207 \mathrm{kPa}$ (30 psi), so the lowest two pressure settings were outside of normal operating conditions. Pressures below this setting were studied because they resulted in a wider range of flow rates for the limited set of nozzles tested.

Another important consideration is that multiple nozzles are typically used at a regular spacing in an actual spraying application. The recommended spacing for the TP800xEVS series nozzle is $50 \mathrm{~cm}$ (20 in.), which will result in overlap across the entire distribution range of each nozzle. In this instance, the as-applied flow rate measured $76 \mathrm{~cm}$ (30 in.) below the nozzle will be the combined flow from two or more nozzles in the near vicinity.

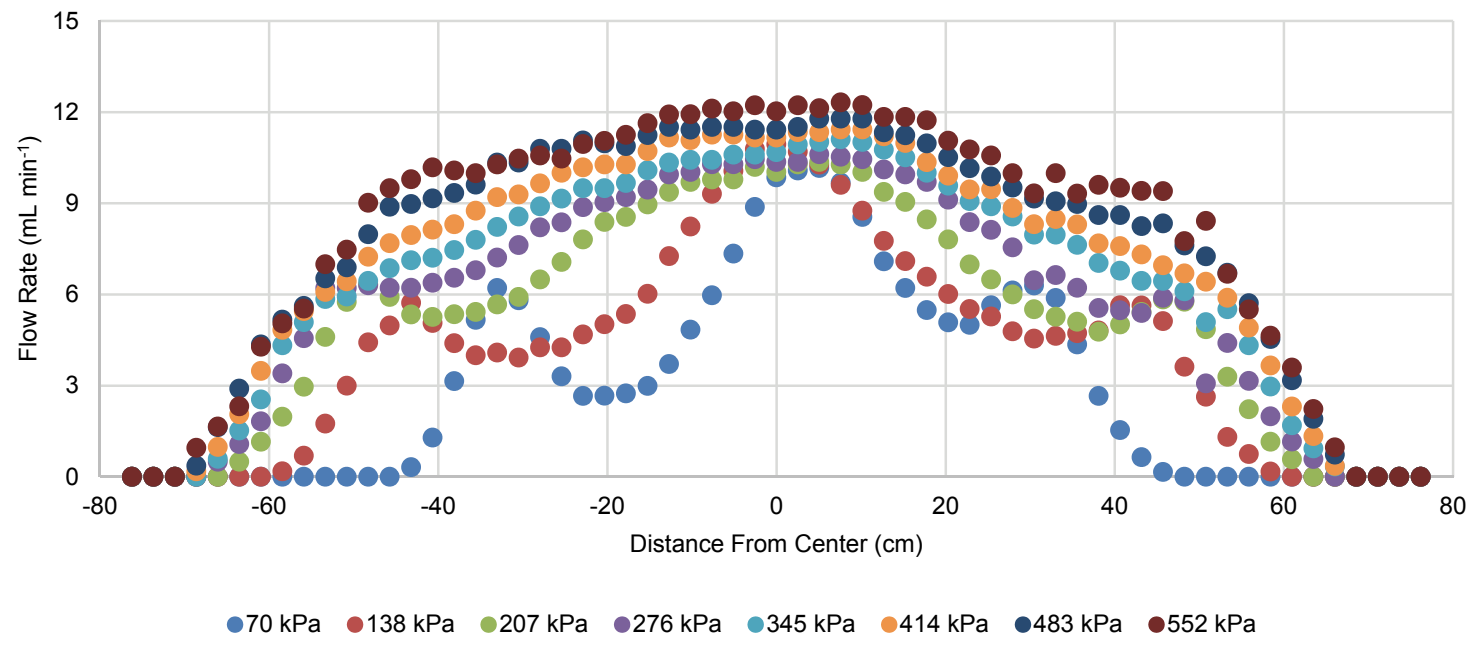

Figure 6. Fine spray nozzle distribution (TP8001EVS).

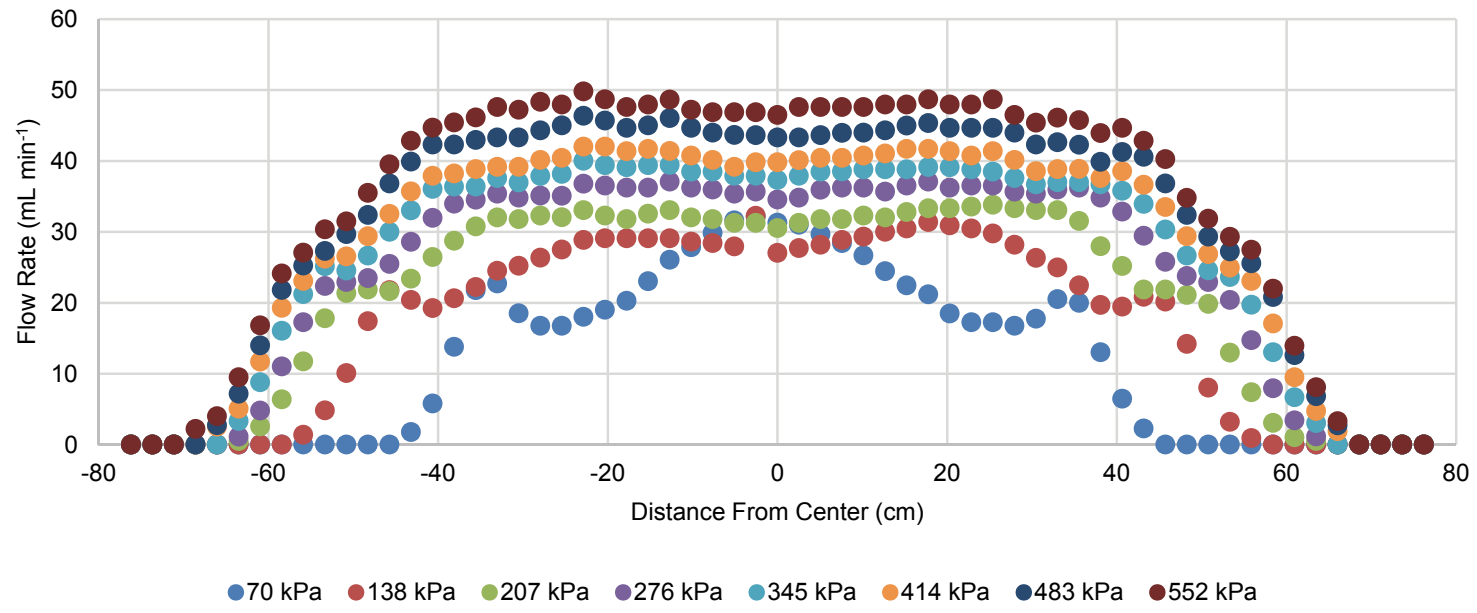

Figure 7. Medium spray nozzle distribution (TP8004EVS). 


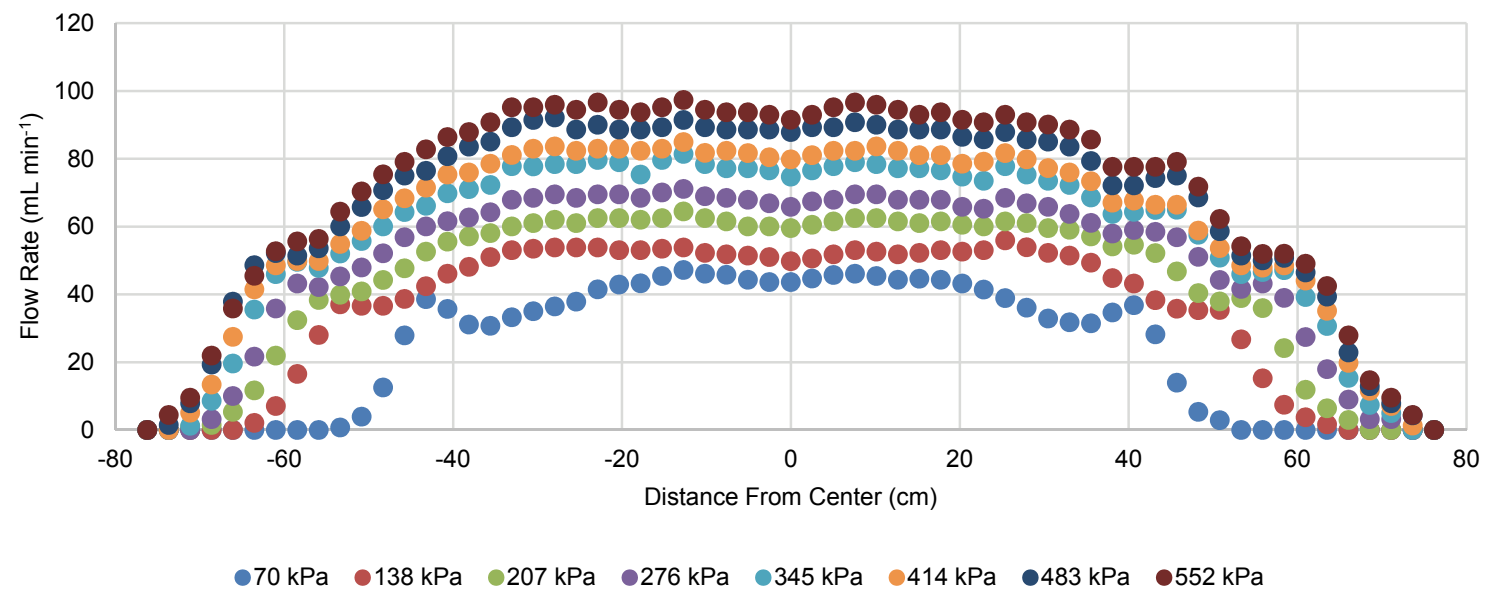

Figure 8. Coarse spray nozzle distribution (TP8008EVS).

\section{Data Processing and ANALYSIS}

Several methods for converting cropped images to grayscale were tested. The cropped images were represented as a three-dimensional matrix, where the first two dimensions were spatial data at a resolution of 4800 pixels per inch and the third dimension represented 24-bit red, green, and blue color data. Initially, the average of the individual color bands was used to produce a grayscale image, but the resulting binary image appeared to contain noise that was not clearly visible on the original or cropped image. Further investigation revealed that the red and green bands did not exhibit the same level of contrast between droplets and the background as the blue color band (fig. 9). The borders surrounding individual droplets appeared to "bleed," which caused droplet area estimations to be artificially larger when using any combination of the red or green bands. The effect was more pronounced with larger droplets and as the spray card was exposed to more droplets, which was consistent with the results from Panneton (2002), where the distance between droplets was noted as a contributing factor to varying background color. Therefore, the grayscale data used to calculate a binary image only consisted of the blue band. While the area of individual droplets in the blue band appeared to be smaller, the results were more consistent across all droplet sizes and spray cards.
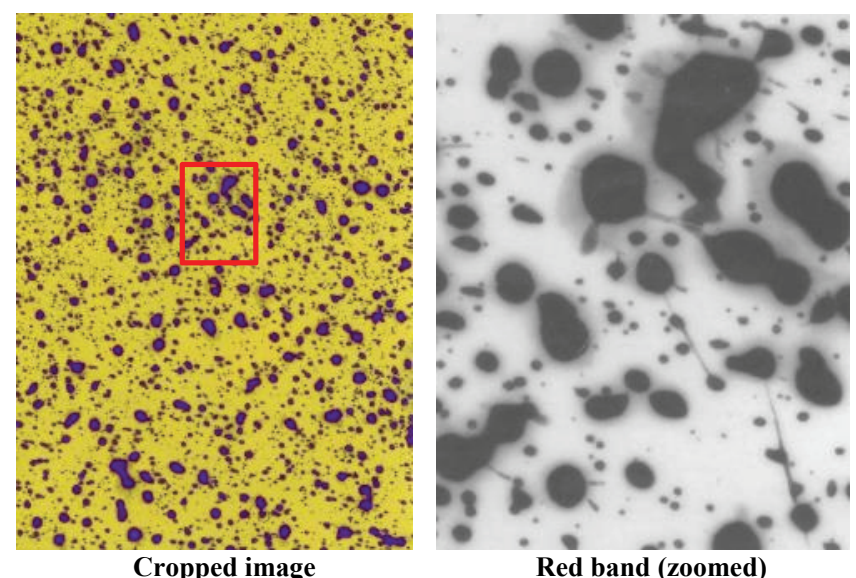

Red band (zoomed)

\section{Calibration Model}

The relationship between nozzle flow rate and spray card coverage for the nozzle series was direct and linear with a small, but noticeable, amount of saturation at higher flow rates (fig. 10). Each point in figure 10 represents the average of three replications, and the error bars are \pm one standard deviation. It is suspected that very high flow rates resulted in more overlap in droplets striking the spray card, which lowered the measured coverage. As a result, the second-order model $\left(\mathrm{R}^{2}=0.936\right)$ produced a slightly better fit than the first-order model $\left(\mathrm{R}^{2}=0.927\right)$.

The distribution in data was unintentionally skewed toward lower flow rates, which was a result of choosing evenly spaced operating pressures across the entire series of nozzles. Deviation from the first-order and second-order models was greatest at flow rates near $0.5 \mathrm{~L} \mathrm{~m}^{-1}$ but also increased for a portion of the mid-range flow rates between 1.7 and $3.0 \mathrm{~L} \mathrm{~m}^{-1}$.

\section{MODEL VALIDATION}

The first-order and second-order regression equations in figure 10 were inverted to solve for flow rate in terms of spray card percent coverage and are shown in equations 1 and 2 . The resulting equations were used as models to estimate the flow rate on the validation data set:
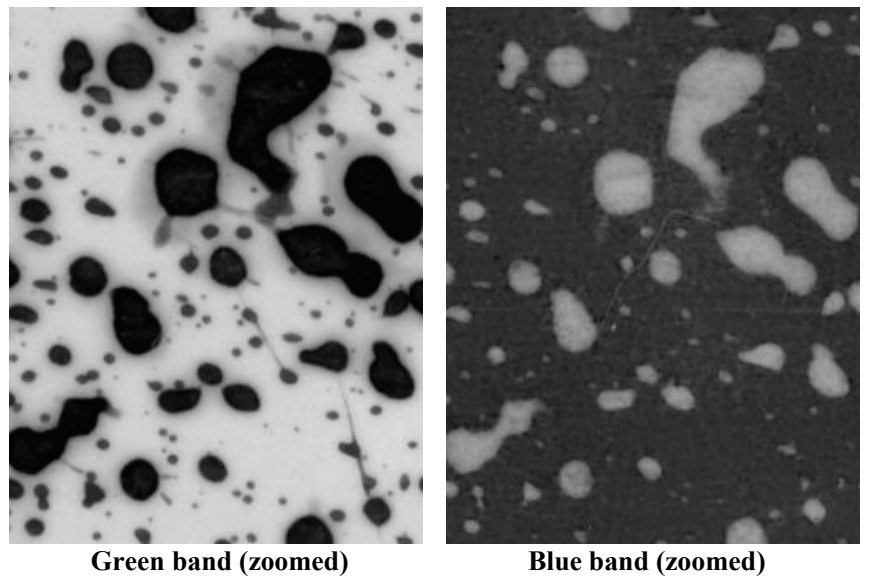

Blue band (zoomed)

Figure 9. Grayscale comparison between red, green, and blue bands from a cropped image. 


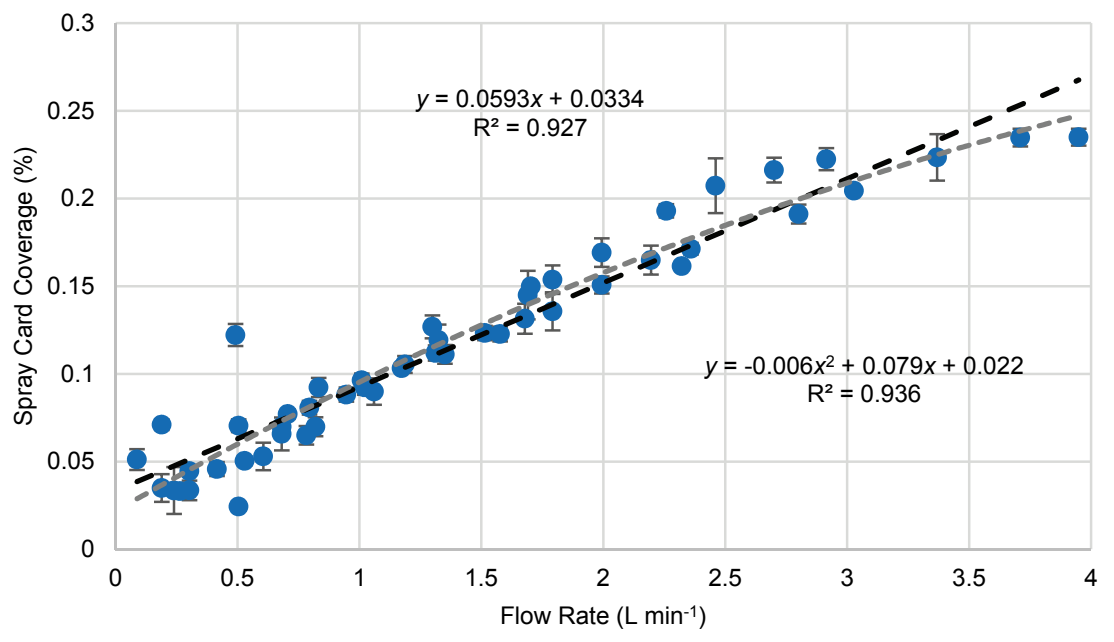

Figure 10. Calibration regression equations for spray card coverage.

First-order model: $\quad \hat{Q}=16.9 C-0.563$

Second-order model: $\hat{Q}=7.11-13.4 \sqrt{0.303-C}$

where $\hat{Q}$ is the estimated flow rate $\left(\mathrm{L} \min ^{-1}\right)$, and $C$ is the spray card coverage (\%).

Figure 11 illustrates the relationship between the estimated and measured flow rates for the first-order and second-order models. Each point represents the average of three replications, and the error bars are \pm one standard deviation. The second-order model was slightly better at estimating the flow rate from spray card percent coverage at lower measured flow rates but provided little to no improvement toward the medium flow rates. Both models tended to overestimate flow rate as the measured flow rate increased. RSME for the first-order and second-order validation data were 0.324 and $0.318 \mathrm{~L} \mathrm{~min}^{-1}$, respectively. The

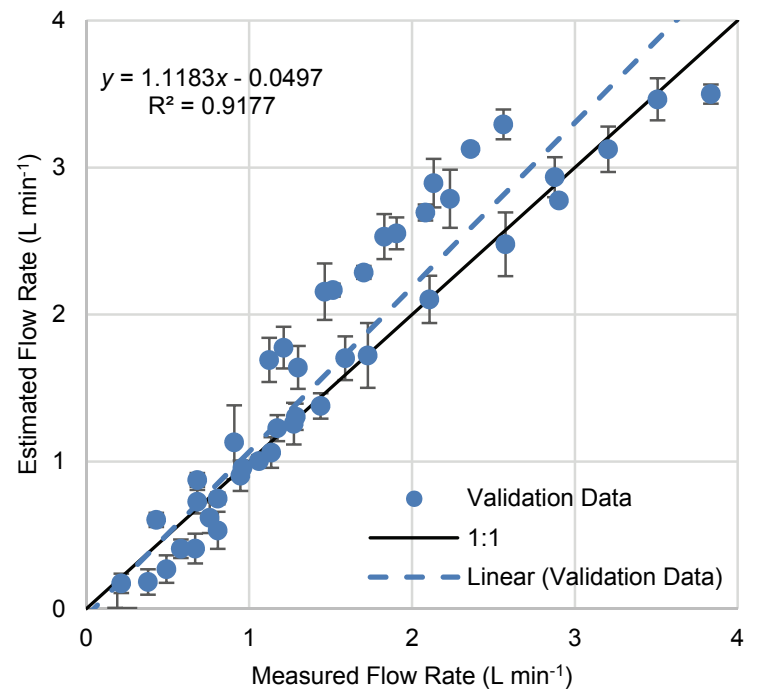

(a) specified accuracy of the flowmeter was $1 \%$ FS, or $0.189 \mathrm{~L}$ $\min ^{-1}$. The degradation in accuracy when using the spray card method to estimate flow rate at a single speed was less than 1\% FS when compared to the flowmeter. Since the flowmeter error could not be accounted for, it likely contributed to a portion of the RSME between the measured and estimated flow rates. An interesting trend was apparent in both models where the data appeared to be grouped along two distinct slopes; however, the source of this discrepancy is unknown.

\section{VARIABLE SPEED RESULTS}

Varying angular velocities were converted to speed by multiplying the angular velocity with the distance between the center of the spray card and the axis of rotation on the rotary test fixture. The speed variation between the outer and inner edges of the spray card was $6.4 \%$ due to rotational motion rather than one-dimensional translation. Speed

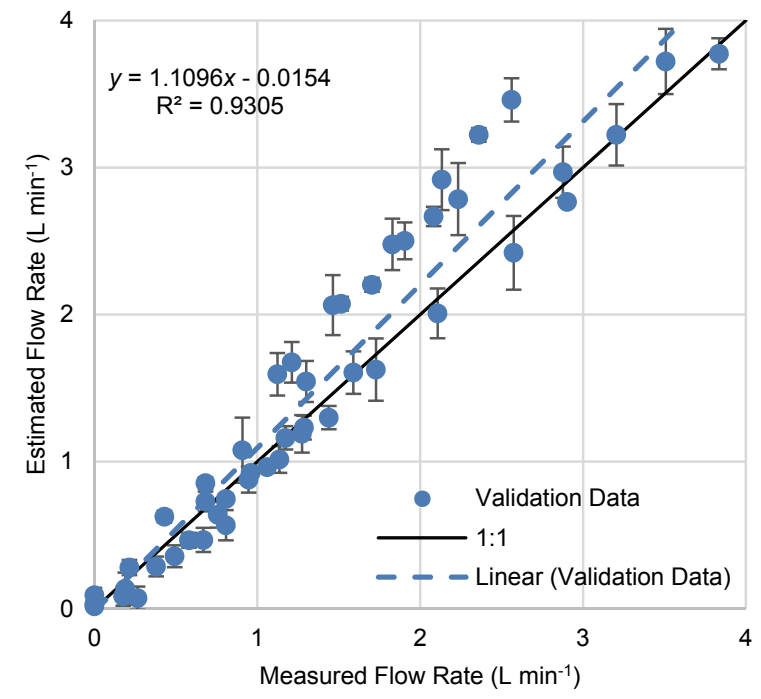

(b)

Figure 11. (a) First-order and (b) second-order model validation. 
variation was ignored for this study, as the effect was expected to average out over the spray card. A reduction in the speed variation could be achieved by using a smaller spray card or increasing the radius of rotation, or eliminated by using a linear test fixture.

Speed of the spray card traveling under the nozzle had an indirect effect on the percent coverage and followed a linear relationship over the range of speeds tested (fig. 12). However, the slope varied from $3 \%$ to $8 \%$ coverage per $\mathrm{m} \mathrm{s}^{-1}$ depending on the nozzle model. Therefore, compensating for speed when making flow rate predictions will require knowledge of the actual nozzle model as opposed to just the nozzle series. Each point in figure 12 represents the average of three replications, and the error bars are \pm one standard deviation. The nozzle with the smallest orifice exhibited the largest amount of variability, particularly at higher speeds.

Further investigation showed that the eccentricity of the exposed droplet at a single flow rate remained relatively constant except for the highest two speeds, which exhibited more eccentricity than the slower speeds. This may have influenced the percent coverage by changing the relationship between droplet volume and the area of the mark left on the spray card, which was visible when plotting speed versus percent coverage (fig. 12) and when observing the spray cards (fig. 13).

\section{CONCLUSIONS}

An individual nozzle was instrumented for pressure and flow measurement and control for comparison with spray card percent coverage. An existing rotary test fixture was modified to move spray cards underneath spray nozzle effluent (water) at varying system pressures and travel speeds. The data showed that water-sensitive spray cards were successful in estimating volumetric flow rate based on percent coverage for an individual nozzle from a single nozzle series under highly controlled conditions. The relationship between percent coverage and flow rate was determined to be linear with saturation after approximately $3.5 \mathrm{~L} \mathrm{~min}^{-1}$ for the particular speed and nozzle type studied. Accuracy of the spray card method was determined to be within $1 \% \mathrm{FS}$ of a commercial impeller flowmeter when operating at a single travel speed. The relationship between speed and percent coverage was also linear. However, the data demonstrated that the individual nozzle model, as opposed to the nozzle series, was needed to compensate for speed due to varying slopes relating speed and percent coverage between nozzle models.

Future work is needed to determine if this process can be applied in the field for validating sprayers under actual operating conditions where boom height, boom speed, and nozzle location with respect to the spray card are not con-

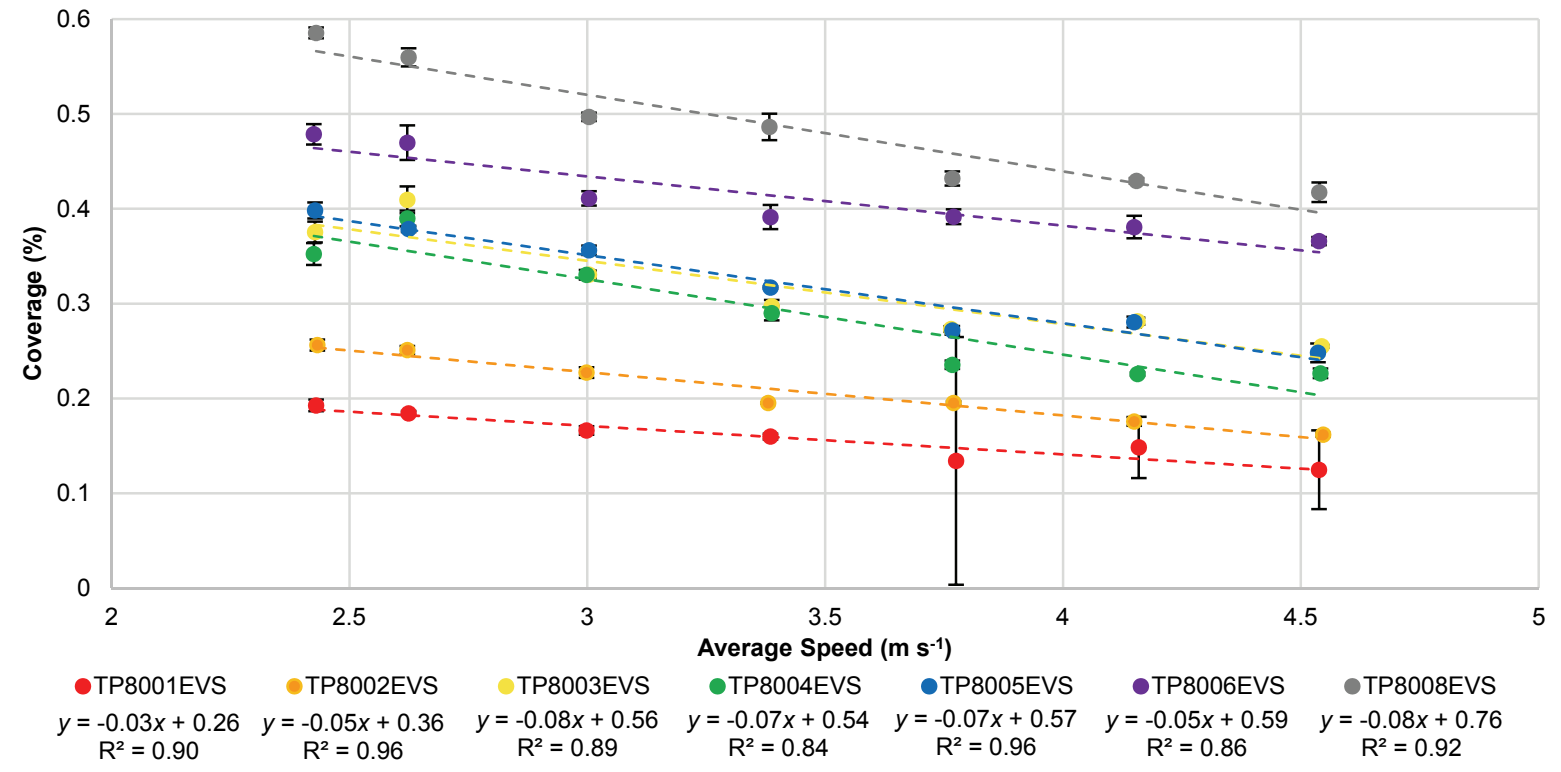

Figure 12. Influence of speed on percent coverage.
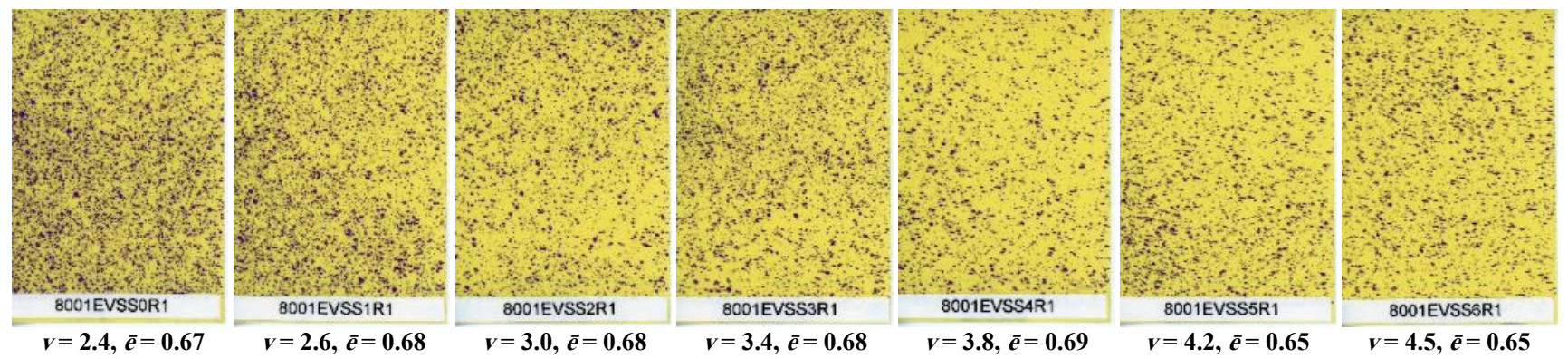

Figure 13. Average eccentricity $(\bar{e}, 1=$ circle and $0=$ line $)$ versus speed $\left(v, \mathrm{~m} \mathrm{~s}^{-1}\right)$ from a single nozzle (TP8001EVS). 
trolled to the same level of precision. A logical step is to perform the same experiment using a linear test fixture where the spray nozzle is moved over the spray card on a straight path. The addition of an adjustable height system will allow for better simulation of field conditions in the laboratory.

The results of these experiments showed that spray cards are a potential tool for validating the liquid flow rate from a single nozzle in addition to their typical use for assessing coverage. While it is expected that this process can be applied to a multiple nozzle system, problems may arise if flow rates exceed the saturation level of the spray card. Determining the exact source of the spray on a multiple nozzle system will also be a challenge, but may not be as important as knowing what the actual flow rate was at the target. Perhaps the most important feature of using spray cards as a validation tool is that they take into account all parameters when determining the system performance, from the sprayer to the environmental conditions under which it operates.

\section{ACKNOWLEDGEMENTS}

This material is based on work supported by the USDA National Institute of Food and Agriculture and the Kentucky Agricultural Experiment Station under Agreement KY005038. Any opinions, findings, or conclusions expressed in this publication are those of the authors and do not necessarily reflect the views of the USDA or the Kentucky Agricultural Experiment Station.

\section{REFERENCES}

Fox, R. D., Derksen, R. C., Cooper, J. A., Krause, C. R., \& Ozkan., H. E. (2003). Visual and image system measurement of spray deposits using water-sensitive paper. Appl. Eng. Agric., 19(5), 549-552.

Franz, E. (1993). Spray coverage analysis using a hand-held scanner. Trans. ASAE, 36(5), 1271-1278. http://dx.doi.org/10.13031/2013.28459

Hoffmann, W. C., \& Hewitt, A. J. (2005). Comparison of three imaging systems for water-sensitive papers. Appl. Eng. Agric., 21(6), 961-964. http://dx.doi.org/10.13031/2013.20026

Jeon, H. Y., Womac, A. R., \& Gunn, J. (2004). Sprayer boom dynamic effects on application uniformity. Trans. ASAE, 47(3), 647-658. http://dx.doi.org/10.13031/2013.16094
Luck, J. D., Pitla, S. K., Zandonadi, R. S., Sama, M. P., \& Shearer, S. A. (2011). Estimating off-rate pesticide application errors resulting from agricultural sprayer turning movements.

Precision Agric., 12(4), 534-545. http://dx.doi.org/10.1007/s11119-010-9199-9

Luck, J. D., Schaardt, W. A., Forney, S. H., \& Sharda, A. (2016). Development and evaluation of an automated spray patternator using digital liquid level sensors. Appl. Eng. Agric., 32(1), 4752. http://dx.doi.org/10.13031/aea.32.11381

Panneton, B. (2002). Image analysis of water-sensitive cards for spray coverage experiments. Appl. Eng. Agric., 18(2), 179-182. http://dx.doi.org/10.13031/2013.7783

Sama, M. P., \& Stombaugh, T. S. (2014). Performance evaluation of a tracking total station as a position reference for dynamic GNSS accuracy testing. Appl. Eng. Agric., 30(4), 557-563.

Sama, M. P., Stombaugh, T. S., \& Lumpp, J. E. (2013). A hardware method for time-stamping asynchronous serial data streams relative to GNSS time. Comput. Electron. Agric., 97, 56-60. http://dx.doi.org/10.1016/j.compag.2013.07.003

Sharda, A., Fulton, J. P., McDonald, T. P., \& Brodbeck, C. J. (2011). Real-time nozzle flow uniformity when using automatic section control on agricultural sprayers. Comput. Electron. Agric., 79(2), 169-179. http://dx.doi.org/10.1016/j.compag.2011.09.006

Sharda, A., Fulton, J. P., McDonald, T. P., Zech, W. C., Darr, M. J., $\&$ Brodbeck, C. J. (2010). Real-time pressure and flow dynamics due to boom section and individual nozzle control on agricultural sprayers. Trans. ASABE, 53(5), 1363-1371. http://dx.doi.org/10.13031/2013.34891

Smith, D. B., Bode, L. E., \& Gerard, P. D. (2000). Predicting ground boom spray drift. Trans. ASAE, 43(3), 547-553. http://dx.doi.org/10.13031/2013.2734

Speelman, L., \& Jansen, J. W. (1974). The effect of spray-boom movement on the liquid distribution of field crop sprayers. $J$. Agric. Eng. Res., 19(2), 116-129. http://dx.doi.org/10.1016/0021-8634(74)90027-4

Turner, C. R., \& Huntington, K. A. (1970). The use of a watersensitive dye for the detection and assessment of small spray droplets. J. Agric. Eng. Res., 15(4), 385-387. http://dx.doi.org/10.1016/0021-8634(70)90099-5

Williamson, R. E., \& Threadgill, E. D. (1974). A simulation for the dynamics of evaporating spray droplets in agricultural spraying. Trans. ASAE, 17(2), 254-261. http://dx.doi.org/10.13031/2013.36835

Zhu, H. P., Salyani, M., \& Fox, R. D. (2011). A portable scanning system for evaluation of spray deposit distribution. Comput. Electron. Agric., 76(1), 38-43. http://dx.doi.org/10.1016/j.compag.2011.01.003 